\title{
An Ecotoxicological Study of a Population of the White Footed Mouse (Peromyscus leucopus) Inhabiting a Polychlorinated Biphenyls-Contaminated Area
}

\author{
Jennifer Batty*1, Richard A. Leavitt**, Natalie Biondo $†$, and Donald Polin $\dagger$ \\ *Museum of Natural History, University of Michigan, Ann Arbor, Michigan 48109, USA, **Pesticide Research Center and, †Department \\ of Animal Science, Michigan State University, East Lansing, Michigan 48824, USA
}

\begin{abstract}
White footed mice (Peromyscus leucopus) inhabiting an area surrounding a pond (Tyler) contaminated with polychlorinated biphenyls (PCBs) and metals (Cadmium, Zinc, Copper) had whole body burdens of $0.42-4.17 \mathrm{ppm}$ PCBs (mean $2.3 \mathrm{ppm}$ ) and animals from a comparison nonpolluted site (WCC) had no detectable PCBs. Males and females caught at the polluted site in the winter months were not significantly different in body weight or length when compared to WCC animals, but Tyler animals had significantly increased relative liver, kidney, spleen and adrenal weights. In the summer months, mostly males were caught at both Tyler and WCC sites. Tyler males were significantly lighter than WCC males, and had a significantly increased relative liver weight when compared to the males from the WCC site. In addition, the adult Tyler males had significantly lower relative testis weights. At Tyler there was a significantly smaller proportion of juveniles and subadults in the population than at WCC. Polychlorinated biphenyls levels in the adult Tyler males were significantly positively correlated with relative liver weight, but there were no significant correlations with any of the other structures measured. These results suggest that at the polluted site there is inhibition of reproduction and changes in liver, spleen, adrenal, and testis function.
\end{abstract}

Polychlorinated biphenyls (PCBs) are industrial chemicals that are widespread global contaminants. They are strongly lipophilic, stable compounds that bioaccumulate and are of major environmental concern (Swain 1983). Their toxicological effects on mammals have been reviewed by Kimbrough et al. (1978) and Sleight (1983) and include changes in the structure and functioning of the liver, spleen, kidney, adrenal and thymus. They are also implicated as carcin-

\footnotetext{
1 Current address: Biology Department, Napier Polytechnic, Colinton Road, Edinburgh EH10 5DT, Scotland, U.K.
}

ogens and cancer promoters. In addition a reduction in reproduction has been reported for many species of mammals (Fuller and Hobson 1987).

Toxicological studies of PCBs in a variety of mammal species have revealed a number of deleterious physiological effects under controlled laboratory conditions. However, in order to ascertain the ecological significance of these observations, it is also important to conduct field studies on natural populations, since a toxic substance may behave differently in the laboratory compared to the field for at least three reasons. First, a substance passing through the food chain may become biotransformed and have different effects from the original pollutant. Such a phenomenon has been reported by Aulerich et al. (1986) where PCBs became more toxic to mink when acquired from rabbits that had been treated with PCBs. Second, the ecological significance of an observed toxicological effect may not be clear from laboratory studies. For example, it has been observed that the number of spermatozoa in the testis of PCBs-treated laboratory mice is decreased (Sanders and Kirkpatrick 1975), but this may not actually decrease reproductive potential in natural populations. Last, laboratory studies of toxicological effects may fail to detect subtle changes in physiology or behavior that may be of no significance in the stable, predictable laboratory environment but may have major effects in the wild. A slightly lowered reaction time may increase the probability of predation (Moriarty 1983), and small changes in thermoregulatory ability may markedly effect winter losses.

Reproductive dysfunction as a result of low levels (less than $10 \mathrm{ppm}$ ) of dietary PCBs has been reported in several species including rhesus monkeys (Barsotti et al. 1976), mink and ferrets (Ringer 1983) and white-footed mice (Linzey 1987). Laboratory rats and mice appear to be more resistant to PCBs, since fewer effects have been observed at these or higher doses (Sanders et al. 1974; Keplinger et al. 1971; Linder et al. 1974). There have been several laboratory studies on effects of PCBs on reproduction in the white footed mouse (Peromyscus leucopus). Studies that most reflect natural ecological conditions are those in which the 
PCBs are administered via the diet in low doses over a long period of time, to genetically varied subjects, such as that of Linzey (1987), in which adult $P$. leucopus were wild caught, paired and then exposed to dietary PCBs (10 ppm Aroclor ${ }^{B}$ 1254) for varying periods of up to 36 weeks in the laboratory. The proportion of pairs breeding and the litter size was the same in both groups, but the survival of pups to 28 days was reduced to $60 \%$ in the PCBs group compared to $83 \%$ in controls. Laboratory born animals exposed to PCBs at twelve weeks of age showed a reduction in the percentage of pairs reproducing ( $53 \%$ in controls, $29 \%$ in PCBs group), an increased birth interval, reduced litter size at birth, and decreased survival of young to 28 days. The overall survival of the pups was $98 \%$ in the controls and only $56 \%$ in the PCB group. Laboratory born animals not exposed to PCBs until sixteen weeks of age did not show effects on the proportion of pairs breeding, the number of litters per female or the birth interval. However, the survival of young to 28 days was reduced (11\% in PCBs treated group and only $61 \%$ in controls). This study also noted that liver aberrations (enlargement plus a pale coloration) were common in animals from all the PCBs treated groups. As Linzey (1987) points out "these results indicate a potential negative effect on populations (lowered juvenile recruitment) exposed to PCBs in the diet."

Other laboratory studies on white footed mice employed higher levels of dietary PCBs over shorter periods of time, but found similar reproductive effects. For example, Merson and Kirkpatrick (1976) fed $P$. leucopus a diet containing 200 ppm PCBs (Aroclor ${ }^{\circledR}$ 1254) and found that only $30 \%$ of the PCB treated pairs reproduced, in contrast to $80 \%$ of the control pairs. No offspring in the PCB treated group survived beyond 21 days of age. Sanders and Kirkpatrick (1977) fed female Peromyscus a diet containing 25 and $100 \mathrm{ppm}$ PCBs for a period of three weeks and found increased liver weights and a reduced plasma corticosteroid level. They found no effects on reproductive organ weights or incidence of estrus as indicated by vaginal smears. Studies on male $P$. leucopus by Sanders and Kirkpatrick (1975) found dietary PCBs at a dose of 200 and 400 ppm to reduce corticosteroids and to reduce the sperm count.

Thus, there is clear laboratory data demonstrating the effects of PCBs on several aspects of physiology, reproduction, and survival in $P$. leucopus. The present study reports data collected from a natural population of $P$. leucopus inhabiting an area heavily polluted with PCBs.

\section{Materials and Methods}

The study site was Tyler Pond, a part of the Willow Creek area near Ann Arbor, Michigan. The site is listed by the U.S. Department of Natural Resources (DNR 1975) as a group 1 priority contaminated site. The surface water, ground water and soil surrounding the pond are heavily contaminated with PCBs and some metals (cadmium, copper, zinc) (DNR 1985). The levels of pollutants at Tyler have been reported by Jurczak (1984) in a study commissioned by the Washtenaw Health Department. The combined levels of PCBs Aroclors $1242,1254,1260$ ) from 11 sediment sampling points range from 0.1-290 ppm, with an average level of $118 \mathrm{ppm}$. The ratio of the three Aroclors is approximately 70:50:1. The average levels of cadmium, copper, and zinc from these sampling points are 48,188 , and $300 \mathrm{ppm}$. The pond is approximately $60 \mathrm{~m}$ wide and $300 \mathrm{~m}$ long and is surrounded by mixed woodland (Northern hardwoods-mixed conifer at different successional stages) that extends between 5-40 meters from the water's edge. The area southeast of the pond is grassy with only a few scattered trees and several small bushes. Half a kilometer to the northeast of the site is a large automobile manufacturing company and to the east there is a small private airport. South of the pond is a small dam, with a moderate flow of water into Willow Run stream which empties into Belleville Lakea local tourist attraction.

An unpolluted site used for comparative purposes was located in the grounds of Washtenaw Community College, east of Ann Arbor, Michigan and also consisted of mixed woodland (as above). Two areas surrounding small ponds within the site were chosen for the study. Area A consisted of mixed woodland surrounding a small pond $(25 \times 20 \mathrm{~m})$ that became almost dry in summer, and Area B consisted of mixed woodland surrounding a permanent pond $(40 \mathrm{~m}$ $\times 150 \mathrm{~m}$ ). At both of these areas most of the woodland extends beyond $500 \mathrm{~m}$ from the waters edge but the eastern side of area $A$ is only $50 \mathrm{~m}$ from a grassy area, and at $B$ the habitat southeast of the pond is grassy with only a few scattered small trees.

For the early part of the study (November 1-12), snap traps (museum specials) were used, but subsequently all animals were live trapped with Longmore traps. Traps were placed in pairs (about one meter apart) between 5 and $40 \mathrm{~m}$ from the waters edge at Tyler and Washtenaw sites, and each pair of traps was separated by a distance of 10 to $15 \mathrm{~m}$. Traps were left in place for two to three consecutive nights, and checked for captures each morning. Traps were either reset with oatmeal bait or moved. Mice were trapped in the late Fall of 1985 (November 1-December 20) on the east and south side of Tyler Pond (but east of the dam) and at control site A, and in Spring and Summer 1986 (June 1-July 31) on the west and south side of Tyler Pond (but west of the dam) and at control site B. The total trap nights for autumn/winter were 180 for both Tyler and WCC and for spring/summer were 400 (Tyler) and 360 (WCC). A trap night is one trap set for one night (actually $24 \mathrm{hr}$ ). Several species of rodent were captured including shrews and voles, but the white footed mouse (Peromyscus leucopus) was the only species captured in sufficient numbers to allow population analysis.

The animals were killed and the following measures taken: total length, body weight, and weights of the liver, kidney, spleen, adrenals and reproductive structures (testes, seminal vesicles, ovaries and uteri). From each animal, part of the liver, one kidney and testis or ovary and uterus were removed and placed in Bouins solution for later histological examination. The reproductive condition of the females (pregnant and/or lactating) was also noted. The pelage was also characterized as either juvenile, subadult or adult.

The carcasses were deep frozen for later PCBs residue analysis by the Pesticide Research Center, East Lansing. Whole body levels of PCBs were determined, since this measure best reflects the toxicological burden to the animal (Moriarty 1983). A 15-20 g sample of finely chopped mouse was blended with $75-100 \mathrm{ml}$ toluene/ethyl acetate $(1: 3)$. The fluid portion was decanted off into a small $(5 \mathrm{~cm})$ Buchner funnel containing a solvent wetted glass fiber filter, under vacuum, into a $250 \mathrm{ml}$ filter flask. The blending and filtering steps were repeated twice and all extracts were combined. The filtered solvent was poured through a glass funnel containing $5 \mathrm{~g}$ anhydrous sodium sulphate into a $500 \mathrm{ml}$ graduated cylinder. The funnel was rinsed with an additional $50 \mathrm{ml}$ solvent and the final volume was adjusted to $500 \mathrm{ml}$. After mixing thoroughly, $50 \mathrm{ml}$ was pipetted into a $250 \mathrm{ml}$ flat-bottomed flask and rotoevaporated to about $5 \mathrm{ml}$ and poured through a small funnel into a $10 \mathrm{ml}$ volumetric flask. The 250 $\mathrm{ml}$ flask was rinsed with several portions of solvent and added to the $10 \mathrm{ml}$ volumetric flask until full.

Each sample was processed through an ABC Labs Autoprep 1001 gel permeation chromatograph (GPC), using Bio Beads S-X3, 200-300 mesh packing and toluene/ethyl acetate (1:3) to remove the 
higher molecular weight materials. 7-8 $\mathrm{ml}$ from the volumetric flask was used to rinse and fill the $5 \mathrm{ml} \mathrm{GPC}$ sample loop. GPC collection was made in a $250 \mathrm{ml}$ flat-bottomed flask. GPC parameters were: Dump, 21; Collect, 15; Wash, $5 \mathrm{~min}$ at a flow rate $5 \mathrm{ml} / \mathrm{min}$. The collected solvent was rotoevaporated to about $5 \mathrm{ml}$ and poured through a small funnel into a $10 \mathrm{ml}$ volumetric flask. The collection flask was rinsed several times, adding each portion to the volumetric flask until full.

Analysis was conducted with a Varian 3700 gas chromatograph (GC) equipped with an electron capture detector and a 6 foot $\times 2$ $\mathrm{mm}$ id glass column containing $3 \%$ OV-1 on Chromsorb W-AW DMCS, 80/100 mesh packing. GC parameters were: column temperature, $200^{\circ} \mathrm{C}$; detector temperature, $270^{\circ} \mathrm{C}$; injector temperature, $220^{\circ} \mathrm{C}$; and $\mathrm{N}_{2}$ carrier gas at $40 \mathrm{ml} / \mathrm{min}$.

Quantitation was done by measuring the peak heights of seven major GC peaks (retention times 3-10 minutes) from the Aroclor ${ }^{\circledR}$ 1254 (Monsanto Chemical Co.) PCB standards that showed little interference in the control animal tissues. Because DDT is a frequent environmental contaminant, the peak closest to the retention time of DDT was not used. The sum of these peak heights was used to quantitate the final sample extracts.

\section{Results}

The mammal species trapped in most abundance was the white footed mouse, but several other species were also caught. Chipmunks (Tamias striatus) were caught at the control WCC site (5) and at the polluted Tyler site (5); voles (Microtus pennsylvanicus) were caught at WCC (1) and at Tyler (4). The jumping mouse (Zapus hudsonius) was seen once at Tyler but not at WCC. Two species of shrew were caught at WCC - the short tailed shrew (Blarina brevicauda: 5) and the masked shrew (Sorex cinereus: 2). No shrew species were caught at Tyler pond.

\section{Peromyscus leucopus Data}

Population Parameters: In the autumn/winter period seventeen animals $(9 \mathrm{M}, 8 \mathrm{~F})$ were caught at the polluted Tyler site and nineteen $(13 \mathrm{M}, 6 \mathrm{~F})$ at the WCC site. There were no significant differences in sex ratio. In the spring/summer period 19 animals $(17 \mathrm{M}, 2 \mathrm{~F})$ were caught at Tyler and $39(28 \mathrm{M}, 11 \mathrm{~F})$ were caught at WCC. Equal trap effort was expended at both sites. There were significantly more males than females at both the polluted Tyler site $\left(\chi^{2} p<0.01\right)$ and the control WCC site $\left(\chi^{2} \mathrm{p}<0.05\right)$. At both sites, over $67 \%$ of the animals caught were males.

Population structure as indicated by pelage characteristics are shown in Table 1 . In the autumn/winter there were approximately equal numbers of adults and subadults but very few juveniles at either site (two at Tyler and none at WCC). There were no significant differences in the proportions of adults, subadults and juveniles between the two sites. In spring/summer, the proportion of adults, subadults and juveniles combined at Tyler was not significantly different from that seen in the autumn/winter ( $G$ test: $G=2.02$, df $1, p>$ 0.05 ), but at WCC there was a large increase in the number of juveniles and subadults in the population ( $G$ test: $G=$ $4.3, p<0.04$ ). Comparison of the population distributions between Tyler and WCC show a greater proportion of juve-
Table 1. Age structure of trapped mice from Tyler and WCC sites

\begin{tabular}{|c|c|c|c|c|c|c|}
\hline & \multicolumn{2}{|l|}{ Adult } & \multicolumn{2}{|c|}{ Subadult } & \multicolumn{2}{|c|}{ Juvenile } \\
\hline & Male & Female & Male & Female & Male & Female \\
\hline \multicolumn{7}{|c|}{ Autumn/Winter ${ }^{a}$} \\
\hline Tyler & 3 & 2 & 4 & 6 & 2 & 0 \\
\hline WCC & 6 & 3 & 7 & 3 & 0 & 0 \\
\hline \multicolumn{7}{|c|}{ Spring/Summer ${ }^{b}$} \\
\hline Tyler & 8 & 2 & 5 & 0 & 4 & 0 \\
\hline WCC & 5 & 3 & 13 & 2 & 10 & 6 \\
\hline
\end{tabular}

a There were no significant differences between Tyler and WCC in proportion of different age classes

b The proportion of juveniles and subadults combined in the populan tion (males and females) was greater at WCC compared with Tyler: $G$ test: $G=5.98 P<0.02$

Table 2. Body size (Mn \pm SE) of animals from Tyler and WCC sites

\begin{tabular}{|c|c|c|c|}
\hline \multicolumn{4}{|c|}{ Autumn/Winter: male and female data combined } \\
\hline Tyler Pond & Adult & Subadult & Juvenile \\
\hline Number of animals & 5 & 10 & 2 \\
\hline Body weight (g) & $20.5 \pm 0.75$ & $16.0 \pm 0.53$ & $10.2 \pm 1.25$ \\
\hline Body length $(\mathrm{cm})$ & $8.7 \pm 0.46$ & $8.5 \pm 0.01$ & $7.6 \pm 0.10$ \\
\hline $\mathrm{BW} / \mathrm{BL}$ ratio & $2.4 \pm 0.06$ & $1.9 \pm 0.05$ & $1.3 \pm 0.16$ \\
\hline WCC Pond & Adult & Subadult & Juvenile \\
\hline Number of animals & 9 & 10 & 0 \\
\hline Body weight (g) & $19.6 \pm 0.47$ & $15.8 \pm 0.31$ & - \\
\hline Body length $(\mathrm{cm})$ & $9.4 \pm 0.11$ & $8.5 \pm 0.16$ & - \\
\hline $\mathrm{BW} / \mathrm{BL}$ ratio & $2.1 \pm 0.04$ & $1.9 \pm 0.03$ & - \\
\hline \multicolumn{4}{|c|}{ Spring/Summer (males only) } \\
\hline Tyler Pond & Adult & Subadult & Juvenile \\
\hline Number of animals & 8 & 4 & 4 \\
\hline Body weight $(\mathrm{g})^{\mathrm{a}}$ & $19.4 \pm 0.42$ & $14.9 \pm 1.09$ & $10.6 \pm 0.49$ \\
\hline Body length (cm) & $9.8 \pm 0.16$ & $9.1 \pm 0.27$ & $8.1 \pm 0.04$ \\
\hline $\mathrm{BW} / \mathrm{BL}$ ratio & $2.0 \pm 0.06$ & $1.6 \pm 0.08$ & $1.3 \pm 0.06$ \\
\hline WCC Pond & Adult & Subadult & Juvenile \\
\hline Number of animals & 5 & 13 & 10 \\
\hline Body weight $(\mathrm{g})^{\mathrm{a}}$ & $21.1 \pm 0.5$ & $15.2 \pm 0.5$ & $11.7 \pm 0.4$ \\
\hline Body length (cm) & $10.4 \pm 0.07$ & $9.5 \pm 0.09$ & $8.5 \pm 0.2$ \\
\hline $\mathrm{BW} / \mathrm{BL}$ ratio & $2.0 \pm 0.04$ & $1.6 \pm 0.04$ & $1.4 \pm 0.03$ \\
\hline
\end{tabular}

a Student ' $\mathrm{t}$ ' test $\mathrm{t}=2.52, \mathrm{df}=11, \mathrm{p}<0.03$

niles and subadults at WCC compared to Tyler ( $\mathrm{G}$ test: $\mathrm{G}=$ $5.98, \mathrm{p}<0.02)$.

Body Size: The mean body weight, length and weight/length ratios of adults, subadults and juveniles from Tyler and WCC are shown in Table 2. The data from winter-caught males and females were pooled, since there were no significant differences between the two sexes. There were no significant differences in body weight, length or weight/length ratio between the Tyler and WCC animals. The data from spring/summer-caught animals shows the characteristics of the males alone because only two females (one pregnant and one lactating adult) were caught at Tyler. Although the WCC males in all age classes were consistently heavier and longer, the only significant difference was in the adult body weights (' $t$ ' test $t=2.25$, df $11, p<0.03$ ). There were no differences 
Table 3. Organ weights $(\mathrm{Mn} \pm \mathrm{SE})$ of animals from Tyler and WCC sites

\begin{tabular}{|c|c|c|c|c|}
\hline & Tyler & WCC & ' $t$ 'a & $\mathrm{P}<$ \\
\hline \multicolumn{5}{|c|}{ Fall/Winter (males and females) } \\
\hline Number of animals & 17 & 19 & & \\
\hline Liver (mg/g BW) & $58.8 \pm 1.7$ & $46.3 \pm 1.6$ & 5.43 & 0.001 \\
\hline Kidney (mg/g BW) & $17.0 \pm 0.4$ & $12.8 \pm 0.5$ & 6.89 & 0.001 \\
\hline Adrenal (mg/g BW) & $0.67 \pm 0.03$ & $0.44 \pm 0.03$ & 4.63 & 0.001 \\
\hline \multicolumn{5}{|c|}{ Spring/Summer (males only) } \\
\hline Number of animals & 17 & 28 & & \\
\hline Liver (mg/g BW) & $66.3 \pm 1.8$ & $58.3 \pm 1.5$ & 3.36 & 0.002 \\
\hline Kidney $(\mathrm{mg} / \mathrm{g}$ BW) & $16.2 \pm 0.6$ & $17.1 \pm 0.4$ & 1.21 & ns \\
\hline Adrenal (mg/g BW) & $0.82 \pm 0.07$ & $0.90 \pm 0.07$ & 0.63 & ns \\
\hline
\end{tabular}

a Student 't' test

Table 4. Spleen weights: Data normalized by Ln transformation and expressed as mean $\pm \mathrm{SEM}$

\begin{tabular}{lcl}
\hline & Tyler Pond & WCC Pond \\
\hline Autumn/winter: data from males and females & \\
Number of animals & 17 & 19 \\
Body weight $(g) \pm$ SEM & $16.64 \pm 0.87$ & $17.59 \pm 0.51$ \\
Ln Mean \pm SEM & $-2.664 \pm 0.211$ & $-3.403 \pm 0.076^{\mathrm{a}}$ \\
(Spleen weight: g) & $(0.069)$ & $(0.033)$ \\
Spring/Summer: data from males only & \\
Number of animals & 17 & 28 \\
Body weight (g) \pm SEM & $16.03 \pm 0.10$ & $14.99 \pm 0.68$ \\
Ln Mean \pm SEM & $-3.480 \pm 0.112$ & $-3.613 \pm 0.09$ \\
(Spleen weight: g) & $(0.031)$ & $(0.027)$ \\
\hline
\end{tabular}

a Student ' $\mathrm{t}$ ' test $\mathrm{t}=3.67$, df $31, \mathrm{p}<0.001$

in body length/weight ratio between Tyler and WCC animals.

Internal Organ Weights: In order to be able to directly compare the organ weights of all the animals in different weight classes from Tyler and WCC the internal organ weights were expressed as $\mathrm{mg} / \mathrm{g}$ of body weight. Body weight was significantly positively correlated with liver and kidney weights for the autumn/winter and spring/summer data from both Tyler and WCC and treatment of the data in this way was justified; data remained normally distributed. The spleen weights were not correlated consistently with body weight and were not normally distributed. Spleen weight comparisons between groups were made, using full spleen weights which were normalized by logarithmic ( $\mathrm{Ln}$ ) transformation. The relative testis and seminal vesicle weights were compared separately within each of the three developmental stages (adult, subadult and juvenile). These structures undergo a pubertal "spurt" in growth and pooling all the data across age classes would not be appropriate.

Data on organ weights is shown in Tables 3 and 4. Animals caught in the autumn/winter period showed no sex difference in organ weights and, therefore, the data was pooled. The animals from the polluted Tyler area had an increased relative liver weight (student ' $t$ ' $t=5.43$, df $34, p<0.001$ ), kidney (student ' $\mathrm{t}$ ' $\mathrm{t}=6.89$, df $34, \mathrm{p}<0.001$ ) and adrenal (student ' $\mathrm{t}$ ' $\mathrm{t}=4.63$, df $32, \mathrm{p}<0.001$ ) tissue compared to
Table 5. Relative weights of testis and seminal vesicles of adults, subadults, and juveniles from Tyler and WCC sites

\begin{tabular}{lccc}
\hline & Adult & Subadult & Juvenile \\
\hline Tyler Pond & & & \\
Number of animals & 8 & 5 & 4 \\
Body weight $(\mathrm{g} \pm \mathrm{SE})$ & $19.4 \pm 0.4$ & $14.9 \pm 1.1$ & $10.6 \pm 0.49$ \\
Testis $(\mathrm{mg} / \mathrm{gBW} \pm \mathrm{SE})$ & $21.9 \pm 1.1^{\mathrm{a}}$ & $12.0 \pm 1.5$ & $6.9 \pm 1.1$ \\
Sem ves $(\mathrm{mg} / \mathrm{gBW} \pm \mathrm{SE})$ & $6.6 \pm 0.9$ & $3.7 \pm 1.3$ & $1.0 \pm 0.08$ \\
WCC Pond & & & \\
Number of animals & 5 & 13 & 10 \\
Body weight $(\mathrm{g} \pm \mathrm{SE})$ & $21.4 \pm 0.5$ & $15.2 \pm 0.5$ & $11.7 \pm 0.4$ \\
Testis (mg/gBW $\pm \mathrm{SE})$ & $26.9 \pm 0.9 \mathrm{a}$ & $16.2 \pm 1.4$ & $8.0 \pm 1.1$ \\
Sem ves (mg/gBW $\pm \mathrm{SE})$ & $7.1 \pm 0.1$ & $3.6 \pm 0.3$ & $1.3 \pm 0.2$ \\
\hline
\end{tabular}

a Student ' $\mathrm{t}$ ' test $\mathrm{t}=3.12, \mathrm{p}<0.01$

the WCC animals. Spleen weights (Table 4) were significantly greater at Tyler compared to WCC (student ' $t$ ' $t=$ $3.67, \mathrm{df}=34, \mathrm{p}<0.001$ ). No data is given for testis, seminal vesicle or uterine tissue, since these structures were very small in all the animals.

In the spring/summer period, mostly males were caught and only this data is shown in the Table. Males from the polluted Tyler area had an increased relative liver weight $(66.3 \mathrm{mg} / \mathrm{g}$ body weight) compared to the WCC animals ( 58.3 $\mathrm{mg} / \mathrm{gBW}$ ) (student ' $\mathrm{t}$ ' $\mathrm{t}=3.36$, df $43, \mathrm{p}<0.002$ ). There were no significant differences in mean relative weights of kidney and adrenal tissue between the Tyler and WCC animals. There were no significant differences in spleen weight (Table 4) between the Tyler and WCC males. The testis and seminal vesicle weights for the adults, subadults and juveniles are shown in Table 5. In all three classes, the relative testis weights were reduced in the Tyler animals, although this was only significant in the adult group (Student ' $t$ ' test $t$ $=3.12, \mathrm{p}<0.01$ ). There were no significant differences in the relative mean seminal vesicle weights, but the adult Tyler males showed a significantly increased variance (' $F$ ' test $\mathrm{F}=129, \mathrm{p}<0.005$ ).

PCBs Levels: The whole body PCBs level for a sample of the male and female adults and subadults caught in the spring/summer are shown in Table 6. The mean PCBs levels for the six adult male Tyler animals measured was $2.5 \pm$ $0.53 \mathrm{ppm}$ and the range between individuals was $0.42-4.17$ ppm. No PCBs were detected in the five adult WCC animals. The mean PCBs levels for the Tyler subadults (3) and juveniles (3) were $1.03 \mathrm{ppm}$ and $1.76 \mathrm{ppm}$, respectively. Only two adult females were caught at Tyler during this period. PCBs were not detected in the pregnant female and a level of $1.10 \mathrm{ppm}$ was detected in the lactating female. No PCBs were detected in the two females from WCC pond area. There was no significant correlation between PCB levels and body weight. The correlation coefficients between PCB levels and internal organ weights were determined for the adult males. There was a significant correlation between PCB levels and relative liver weights $(r=0.81$, df $4, p<0.05$ ) in the adult males, but there was no significant correlation when data from all the males was pooled together. There were no significant correlations with relative kidney, adrenal, spleen, testis or seminal vesicle weights. 
Table 6. Whole body PCB levels in males and females from Tyler and WCC sites: mean \pm SEM

\begin{tabular}{lll}
\hline & Tyler Pond & WCC Pond \\
\hline Males & & \\
Adults (No. of animals) & $(6)$ & $(5)$ \\
Body weight (g) \pm SEM & $19.7 \pm 0.5$ & $19.3 \pm 0.6$ \\
PCB (ppm) \pm SEM & $2.50 \pm 0.53$ & $\mathrm{ND}^{*}$ \\
Range & $0.42-4.17$ & - \\
Subadults (No. of animals) & $(3)$ & $(-)$ \\
Body weight (g) \pm SEM & $13.6 \pm 1.2$ & - \\
PCB (ppm) \pm SEM & $1.03 \pm 0.45$ & - \\
Range & $0.17-1.66$ & - \\
Juveniles (No. of animals) & $(3)$ & $(-)$ \\
Body weight (g) \pm SEM & $10.3 \pm 0.5$ & - \\
PCB (ppm) \pm SEM & $1.76 \pm 0.47$ & - \\
Range & $1.30-2.70$ & - \\
Females & & \\
Adults (No. of animals) & $(2)$ & $(2)$ \\
Body weight (g) \pm SEM & $19.1 \pm 2.5$ & $17.6 \pm 1.1$ \\
PCB (ppm) & $1.10^{\mathrm{b}}, \mathrm{ND}^{\mathrm{a}}$ & $\mathrm{ND}^{\mathrm{a}}$ \\
\hline
\end{tabular}

${ }^{a}$ None Detectable: detection limit $0.1 \mathrm{ppm}$

${ }^{b}$ Lactating

\section{Discussion}

The mammal species trapped in most abundance at both the study sites was Peromyscus leucopus which, therefore, became the focus of the study. In addition, some voles were caught at both sites suggesting that the habitat was secondary for $P$. leucopus. Two shrew species were caught at the unpolluted WCC site, but none at the polluted Tyler site. This lack of shrews at Tyler may be of some significance since many studies have found mammal species high on the food chain to be particularly susceptible to heavy metal and polychlorinated biphenyls pollution (Scanlon 1987; Tanabe 1988).

Peromyscus leucopus living in the polluted Tyler pond area showed marked differences in both population parameters and anatomical features when compared to animals from the non-polluted WCC area. In the winter months there were no differences in population structure between Tyler pond and WCC, but during the breeding season there were markedly fewer juvenile animals at Tyler, suggesting that this population was not reproducing successfully. The body weights and lengths for adults, subadults and juveniles were equivalent in animals from the two sites in the autumn/ winter months, but in the summer months the Tyler animals were significantly lower in body weight. There were increases over all age classes in the relative weights of liver, kidney, adrenal and spleen tissue of winter caught animals, but in the summer months only the liver weight was significantly elevated in the Tyler animals. In addition, the relative testis weights were reduced in the adult Tyler animals and the relative seminal vesicle weights showed an increased variance compared to the WCC males. Polychlorinated biphenyls were detected in the Tyler animals at between 0.42 and $4.17 \mathrm{ppm}$ (whole body level) and these levels were significantly positively correlated with relative liver weight. PCBs were not detected in the animals in the control WCC site.
In the autumn/winter season, there were no significant differences in sex ratio at either WCC or Tyler sites. During the spring/summer, however, there was a marked increase in the proportion of males caught at both sites to $67 \%$ at WCC and $89 \%$ at Tyler. Such a high proportion of males has been found in other studies of this species. A study by Mannville (1956) found that of $90 \mathrm{P}$. leucopus trapped in Michigan woodland in January to March, $75 \%$ were male. It has been suggested that the large proportion of males caught may be due to their greater movement in the area, which leads to increased exposure to traps (Townsend 1935). It may also be that females, particularly during the breeding season, are less inclined to approach novel objects (traps) in their home range.

The proportion of juveniles and subadults caught at the control WCC site in the spring/summer was significantly greater than the proportion caught in the autumn/winter period. This suggests the population was successfully reproducing during the summer months. However, at the Tyler pond site there was no significant increase in the proportion of juveniles and subadults in the summer population, suggesting that the Tyler population was not successfully reproducing. This lack of juveniles at Tyler is unlikely to be due to residual effects of the winter trapping, since different parts of the study sites were trapped at each season. In addition, emigration is an unlikely explanation, since Peromyscus of several species remain in the natal home range until the subadult dispersal period (Stickel 1968). A lack of juveniles and subadults could also be a result of increased predation pressure. However there is no indication of why this might be the case at Tyler.

The mean pooled body weights of males and females from WCC and Tyler sites were not significantly different during the winter months. In the spring/summer months, the adult males from the control WCC site were significantly heavier than the adult males from Tyler. This difference in weight may be accounted for by differences in the age of the individuals in the adult population. The average body length of the aduits caught at WCC was greater (although not significantly) than those from Tyler, suggesting that they may be slightly older. Laboratory studies of $P$. leucopus have shown that body length and weight continue to increase, at least up to 385 days of age (Lackey 1973). Tyler adults may either be slightly smaller and lighter than the WCC animals, or they may have a shorter life span and, therefore, younger smaller adults may have been caught at that site.

The relative liver weights of Tyler pond animals were significantly higher than those from WCC in both the autumn/ winter and spring/summer periods. Liver weight can vary as a result of atrophy, hypertrophy and/or changes in glycogen or fat content. The increased liver weight seen in Tyler animals may largely be due to hypertrophy since this increased weight was seen over both winter and summer conditions when food supply and metabolic demands vary considerably. Laboratory studies of the effect of variation of food supply on P. leucopus (Sanders and Kirkpatrick 1977) have shown that an ad lib food supply compared to a $70 \%$ food supply produces only a $6 \%$ change in liver weight. Animals from Tyler pond show $27 \%$ and $14 \%$ increases in liver weight compared to WCC animals in winter and summer, respectively, suggesting that variation in food supply alone is unlikely to explain these results. 
The relative kidney weights of Tyler pond animals were significantly greater than those of WCC animals during the autumn/winter months, but were not significantly different during the summer months. Although statistical comparison between the WCC winter males and females combined and the summer males cannot strictly be made, it would appear that during the autumn/winter period the relative kidney weights of the WCC animals were particularly low. The biological significance of this is not clear, but large variations in relative kidney weight at different times of year have been reported for other mammalian species such as the redbacked vole and the Steppe lemming (Schvarts 1975).

The relative adrenal gland weight was significantly increased in animals from the polluted Tyler site compared to WCC animals in the autumn/winter period, but there was no significant difference in adrenal weights in the spring/ summer period, an increase that could be related to a variety of social and physiological factors. For example, Southwick (1964) demonstrated that adrenal weights of laboratory housed subordinate $P$. leucopus are markedly increased in comparison to dominant animals, and therefore the increased adrenal weight at Tyler could be related to increased social stress.

The spleen weights were significantly increased in the Tyler pond population compared to the WCC population during the autumn/winter period, but there was no significant difference in spleen weight in the spring/summer. Spleen hypertrophy can occur in response to several conditions such as, for example, haemolysis caused by trypanosome blood parasites. The increased spleen weight in Tyler animals may reflect an increased burden of blood parasites and other infections during the winter period.

The mean relative testis weights of the Tyler adult males were significantly lower than the WCC males in the summer period. This reduced testis weight may indicate a delayed maturation in Tyler animals or may reflect a more generalised change in the sexual development of these animals. It is well established in other rodents such as the house mouse that variations in the levels of neonatal androgens influence the adult testis weight (Batty 1979; Vale et al. 1974) and the changed adult testis weights of the Tyler animals may reflect altered androgen levels during the neonatal period. Seminal vesicle mean weights were not significantly different between the Tyler and WCC males, but there was an increased variability in the Tyler pond animals. Seminal vesicle weights are dependent on the levels of circulating androgens, and increased variability in seminal vesicle weight suggests there may be increased variability in testosterone level. These combined germinal effects may have a negative influence on the reproductive success of these animals.

Polychlorinated biphenyls were detected in the tissues of the Tyler pond animals, but not in the WCC animals. The whole body PCB levels for the Tyler animals examined ranged between 0.42 and $4.17 \mathrm{ppm}$, with a mean level of 2.3 ppm. There was no significant correlation with body weight, and inspection of the data suggested that the mid weight subadult animals had a lower PCBs burden. This may be because these are recent arrivals at the Tyler site, since subadults do not stay in their natal area but disperse to new sites (Stickel 1968). There was a significant positive correlation of relative liver weight and whole body PCBs burden, suggesting PCBs may be directly involved in liver tissue change.

The $P$. leucopus population at the polluted Tyler site is very different to the population at WCC pond. At Tyler pond, there are high sediment levels of cadmium, copper and zinc, as well as high levels of PCBs, and the possible contribution of these to the effects seen in $P$. leucopus are discussed separately.

Elements essential to animals, such as zinc and copper are better regulated in mammals than non-essential metals, such as cadmium (Goyer 1986). Two reports on the levels of heavy metals in Peromyscus leucopus inhabiting contaminated areas did not find increased concentrations of zinc or copper but did observe elevated concentrations of cadmium (Anthony and Kozlowski 1982; Scanlon 1987). In addition, both zinc and copper have a relatively low potential for toxicity in mammals (Goyer 1986). Thus, it would seem unlikely that the effects seen in this present study are related to zinc or copper poisoning.

Cadmium is highly toxic to virtually every system in the mammalian body (Samarawickrama 1979). The reproductive system in males is particularly sensitive to cadmium exposure with marked decreases in the weights of the testis and the seminal vesicles in rats and house mice (Parizek 1957; Saksena et al. 1977) and hamsters (Lau et al. 1978) at doses that have no apparent effect on other organs. In adult male rats the average testis weight 15 days after the injection of 1 mg cadmium chloride was $47 \%$ that of control animals, and the seminal vesicle weights were $58 \%$ of controls (Saksena et al. 1977). It should be noted that cadmium-induced toxicity is influenced by a variety of factors (Goyer 1986), such as the mode of administration and the dosing regime. Cadmium chloride (up to $68 \mathrm{ppm}$ ) administered via the drinking water to hooded rats for 70 days did not produce changes in testis weight or morphology, and subsequent matings to non-treated females revealed no change in litter size or birth weights (Zenick et al. 1982). Similarly, pairs of house mice exposed to cadmium, both prenatally and throughout adulthood, did not show significant changes in the number of litters, average litter size or interval between litters, but a second generation bred from these subjects did show a reduction in reproductive output (Schroeder and Mitchener 1971). In the deer mouse (Peromyscus maniculatus), exposure to $1 \mathrm{ppm}$ cadmium chloride in the drinking water for a year resulted in two of the six exposed pairs becoming infertile, while the controls remained fertile throughout the test period. Mice born to these pairs were maintained on the cadmium treatment and when mature were mated (avoiding sibling pairs) and breeding success recorded. Eight of the 10 cadmium-exposed pairs produced offspring, compared with the control pairs. There was, however, no change in birth weights or fetal survival. In view of these laboratory findings on the effects of cadmium on breeding success, cadmium poisoning could be a contributing factor in the reduced proportion of juveniles observed at Tyler Pond.

Cadmium is also toxic to other organs, and when administered in high doses results in several pathophysiological changes in many mammal species (Samarawickrama 1979). However, animals exposed chronically to low doses of dietary cadmium may reveal effects more related to questions about the environmental effects of cadmium contamination. 
Weigel et al. (1987) exposed weanling male rats to a diet containing cadmium (biologically bound in ryegrass) for 8 weeks. Food intake was reduced in the cadmium exposed group, and there was a $6 \%$ reduction in weight compared to controls after 8 weeks of exposure. Haematological parameters (haemoglobin, haematocrit, blood glucose) were not affected. Analysis of several enzyme systems did not suggest any change in liver function, and there was no change in liver to body weight ratio. In addition, no change was found in the relative weights of spleen, kidney and testis. In view of the lack of effects of dietary cadmium on these organ weights in rats, it would seem less likely that cadmium poisoning is the cause of the changes in these same organ weights observed in Peromyscus from Tyler Pond.

The other major pollutants at Tyler Pond are the polychlorinated biphenyls. PCBs administered in the diet have marked negative effects on reproductive output and survival of young (Merson and Kirkpatrick 1976; Linzey 1987). The present study found that in a population of animals with detectable PCB levels there was a reduction in successful reproduction, indicated by absence of juveniles during the breeding season. Sanders and Kirkpatrick $(1975,1977)$ examined the effects of dietary PCBs on testis and seminal vesicle weights and found no significant effect on testis weight but some reduction in seminal vesicle weight at high doses. The present study found a reduction in testis weight and increased variability (but no difference in mean) in seminal vesicle weight in Peromyscus from a PCB polluted area.

Liver weight has been reported by Sanders and Kirkpatrick (1977) to increase by $25 \%$ in $P$. leucopus fed $25 \mathrm{ppm}$ PCB in the diet. The present study found that relative liver weight was $27 \%$ greater in animals living at a PCB polluted site in autumn/winter and $14 \%$ greater in the spring/summer. PCB levels in individual animals were positively correlated with relative liver weight which supports that they may be causal factors in this response. Sanders and Kirkpatrick (1977) also examined adrenal glands but found no change in weight, although an earlier study by the same authors in 1975 found dietary PCBs to reduce corticosteroid levels. The present study found increased adrenal gland weight in PCBs exposed animals, indicating changes in adrenal function, but the effects on corticosteroid levels remain to be investigated. These observations suggest the effects observed in the Tyler animals may be due to PCBs poisoning.

In conclusion, the negative effects seen in the wild population of $P$. leucopus examined in this study concur with laboratory derived data on the effects of PCBs and cadmium. Whether PCBs, cadmium or a combined effect of the two are involved require further investigation both in the field and the laboratory.

Acknowledgments. The first author (JB) gratefully acknowledges the Museum of Zoology, University of Michigan, for the provision of laboratory facilities during the course of this work, and specifically to Drs. Phil Myers and Paul Heidemann (Mammal Division). Acknowledgments are also due to Washtenaw Community College and the Ypsilanti Community Utilities Authority for permission to trap at WCC and Tyler Pond sites.

\section{References}

Anthony RG, Kozlowski R (1982) Heavy metals in tissues of small mammals inhabiting waste-water-irrigated habitats. J Environ Qual 11:20-22
Aulerich RJ, Ringer RK, Safronoff J (1986) Assessment of primary and secondary toxicity of Arochlor ${ }^{\circledR} 1254$ to mink. Arch Environ Contam Toxicol 15:393-399

Barsotti DA, Marler RJ, Allen JR (1976) Reproductive dysfunction in rhesus monkeys exposed to low levels of polychlorinated biphenyls (Arochlor 1254). Fd Cosmet Toxicol 14:99-103

Batty $J$ (1979) Influence of neonatal injections of testosterone prom pionate on sexual behaviour and plasma testosterone levels in the male house mouse. Devel Psychobiol 12(3):231-238

DNR (1985) Michigan Sites of Environmental Contamination Priority List, Dept of Natural Resources, Lansing, MI 48909

Fuller GB and Hobson WC (1987) Effect of PCBs on reproduction in mammals. In: Waid JS (ed) PCBs and the environment Vol 2, CRC Press 101-125

Goyer RA (1986) Metals. In: Klaassen CD, Amdur MO and Doull J (eds) Cassarett and Doull's Toxicology. Macmillan, New York, $582-635$

Jurczak EJ (1984) Extent of contamination study, Willow Run site, Washtenaw and Wayne Counties, Michigan. Washtenaw County Health Department, Ann Arbor, MI

Keplinger ML, Fancher OE, Calandra JC (1971) Toxicological studies with polychlorinated biphenyls. Toxicol Appl Pharmacol 19:402-403

Kimbrough RD, Buckley J, Fishbein L, Flamm G, Kasza L, Marcus W, Shibco S, Teske R (1978) Animal Toxicol Environ Health Perspect 24:173-185

Lackey JA (1973) Reproduction, growth and development in high latitude and low latitude populations of Peromyscus leucopus (Rodentia). Doctoral dissertation University of Michigan, Ann Arbor

Lau IF, Saksena SK, Dahlgren L and Chang MC (1978) Steroids in the blood serum and testis of cadmium chloride treated hamsters. Biol Reprod 19:886-889

Layne JN (1968) Ontogeny. In: King JA (ed) Biology of Peromyscus. Special publication number 2, American Society of Mammalogists 148-253

Linder RD, Gaines TB, Kimbrough RD (1974) The effect of polychlorinated biphenyls on rat reproduction. Food Cosmet Toxicol 12:63 77

Linzey AV (1987) Effects of chronic polychlorinated biphenyls exposure on reproductive success of white-footed mice (Peromyscus leucopus) Arch Environ Contam Toxicol 16:455-460

Manneville RH (1956) Unusual sex ratio in Peromyscus. J Mammal 37:122

Merson MH, Kirkpatrick RL (1976) Reproductive performance of captive white footed mice fed a PCB. Bull Environ Contam Toxicol 16:392-398

Moriarty F (1983) Ecotoxicology. Academic Press, London

Parizek J (1957) The destructive effect of cadmium ion on testicular tissue and its prevention by zinc. J Endocrinol 15:56-63

Ringer RK (1983) Toxicology of PCBs in mink and ferrets. In: D'Itri FM and Kamrin MA (eds) PCBs: human and environmental hazards. Butterworth Ann Arbor Science 227-240

Saksena SK, Dahlgren L, Lau IF and Chang MC (1977) Reproductive and endocrinological features of male rats after treatment with cadmium chloride. Biol Reprod 16:609-613

Samarawickrama GP (1979) Biological effects of cadmium in mammals. In: Webb M (ed) Topics in environmental health, Vol 2: The chemistry, biochemistry and biology of cadmium. Elsevier/North Holland Biomedical Press, Amsterdam, pp. 341-421

Sanders OT, Zepp RL, Kirkpatrick RL (1974) Effects of PCB ingestion on sleeping times, organ weights, food consumption, serum corticosterone and survival of albino mice. Bull Environ Contam Toxicol 12:394-399

Sanders OT, Kirkpatrick RL (1975) Effects of a polychlorinated biphenyl (PCB) on sleeping times, plasma corticosteroids and testicular activity of white-footed mice. Environ Physiol Biochem $5: 308-313$ 
(1977) Reproductive characteristics and corticoid levels of white footed mice fed ad libitum and restricted diets containing a polychlorinated biphenyl. Environ Res 13:358-363

Scanlon PF (1987) Heavy metals in small mammals in roadside environments: Implications for food chains. The Science of the Total Environment 59:317-323

Schroeder HA, Mitchener M (1971) Toxic effects on the reproduction of mice and rats. Arch Environ Health 23:102-106

Schvarts SS (1975) Morphophysiological characteristics as indices of population processes. In: Golley FB, Petrusewicz $\mathbf{K}$ and Ryszkowski L (eds) Small mammals: Their productivity and population dynamics. Cambridge University Press, Cambridge, UK, pp. 129-152

Sleight SD (1983) Pathological effects of PCBs in mammals. In: D'Itri FM and Kamrin MA (eds) PCBs: Human and environmental hazards. Butterworth Ann Arbor Science 215-226

Southwick C (1964) Peromyscus leucopus: An interesting subject for studies of socially induced stress responses. Science 143:55

Stickel LF (1968) Home ranges and travels. In: King JA (ed) Biology of Peromyscus (Rodentia). Special publication number 2 American Society of Mammalogists 373-542
Swain WR (1983) An overview of the scientific basis for concern with polychlorinated biphenyls in the Great Lakes. In: D'Itri FM and Kamrin MA (eds) PCBs: Human and environmental hazards. Butterworth Ann Arbor Science 11-48

Tanabe S (1988) PCB problems in the future: Foresight from current knowledge. Environ Pollut 50:5-28

Townsend M (1935) Studies on some of the small mammals of central New York. Roosevelt Wildl Ann 4:1-120

Vale JR, Ray D, Vale CA (1974) Neonatal androgen treatment and sexual behavior in males of three inbred strains of mice. Devel Psychobiol 7(5):483-488

Weigel HJ, Ilge D, Elmadfa I, Jäger H-J (1987) Availability and toxicological effects of low levels of biologically bound cadmium. Arch Environ Contam Toxicol 16:85-93

Zenick H, Hastings L, Goldsmith M, Niewenguis RJ (1982) Chronic cadmium exposure: Relation male reproductive toxicity and subsequent fetal outcome. J Toxicol Environ Health 9:377-387

Manuscript received July 15, 1988 and in revised form February 11, 1989. 